\title{
Gildo Marçal Bezerra Brandão (1949-2010) Um Analista do Pensamento Brasileiro
}

\author{
Elide Rugai Bastos
}

$\mathrm{F}_{\text {do fomos parceiros de trabalho durante muitos anos e empreende- }}^{\text {alar de um amigo que nos deixou é muito penoso, sobretudo quan- }}$ mos, com orientandos e ex-orientandos, uma investigação em conjunto. Continuamos a dialogar com ele e a endereçar-lhe perguntas diante das dúvidas e dos embates; e, agora, como a resposta não se faz pronta como sempre o foi, assalta-nos a perplexidade. A ausência se faz sentir mais fortemente quando voltamos a reler seus textos, tantas vezes discutidos e que fundamentaram nossa reflexão. A morte inesperada de Gildo Marçal Brandão deixou um grande vazio entre nós.

O diálogo que nos aproximou e permitiu trabalho conjugado tem seu eixo na reflexão sobre o pensamento político-social brasileiro e se explicita principalmente em um projeto temático em desenvolvimento. O projeto Linhagens do Pensamento Político-Social Brasileiro recebeu o nome do último livro de Gildo e reúne pesquisadores da Universidade de São Paulo (USP), da Universidade Federal do Rio de Janeiro (UFRJ), da Universidade Estadual de Campinas (Unicamp), da Universidade Federal de São Carlos (UFSCar) e da Universidade Federal de São Paulo (Unifesp). Suas hipóteses estão ancoradas direta ou indiretamente nas provocações levantadas nesse texto.

Embora pareça, à primeira vista, não haver continuidade entre a pesquisa desenvolvida sobre a gênese e o papel político da esquerda brasi-

DADOS - Revista de Ciências Sociais, Rio de Janeiro, vol. 53, n- 1, 2010, pp. 5 a 10. 
leira, que resultou no livro A Esquerda Positiva: As Duas Almas do Partido Comunista (1920-1960), publicado em 1997, e o resultado das investigações seguintes, há uma relação intrínseca entre as duas formulações. Gildo várias vezes lembrou que aquele amplo estudo deixou um saldo de hipóteses, argumentos, reflexões sobre o modo de tratar a relação entre ideias e processos políticos. Esse conjunto de questões o levou a pensá-las em outros contextos, em outras configurações históricas. Assim, a temática da organização do poder, que o desafiara desde sempre, fazendo-se presente nos textos anteriores àquele livro, encontrou outro campo de desenvolvimento: o pensamento político brasileiro. Dessa forma, as categorias intelectuais e as formulações políticas implicadas na construção do Estado nacional no século XIX passaram a ser o objetivo de suas preocupações. A seguir, buscou compreender outros momentos dessa edificação, ou, como se referia, tomou o fio de outra meada. Ou seja, buscou, na história das ideias que os brasileiros pensaram ou aclimataram, a via de acesso para a compreensão da sociedade que construíram. O centro de interesse, como expressa no memorial para seu concurso de titularidade, são as relações entre teoria política e história das ideias, entre visões de mundo e instituições políticas, entre o mundo das ideias e o mundo da ação política.

O passo seguinte consistiu na difícil elaboração da abordagem desse objeto. Partindo do princípio de que a construção da Nação e a do Estado são momentos de um longo processo, formula as hipóteses metodológicas que constituirão pontos de partida analíticos sobre os quais repousa a pesquisa do pensamento brasileiro. O desenho desse procedimento é explicitado em Linhagens do Pensamento Político Brasileiro, publicado em 2007, que tem por base sua livre-docência defendida em 2004, no qual a sugestão fundamental é a afirmação de serem as ideias forças sociopolíticas. Em decorrência, aborda o pensamento e as ciências sociais como componentes internos das práticas e das instituições; esses componentes constituem ainda conjunto de referências que servirão de apoio aos embates políticos.

Ao afirmar a presença de linhagens no pensamento político brasileiro, Gildo não pressupõe a existência de uma linearidade ou de um traço evolutivo que unifica as ideias. Supõe continuidades e rupturas entre elas. Afirma não existirem matrizes ideológicas transtemporais. Desse modo, procura equilibrar duas formas de compreensão do pensamento: de um lado os elementos teóricos fundantes das ideias; de outro, o contexto histórico em que são gestadas, desenvolvidas, modificadas e 
aplicadas às situações concretas. A partir dessa difícil combinação, aponta as "afinidades eletivas" existentes entre autores que, por vezes, nem mesmo se dão conta desse fato. Tais encontros ocorrem tanto a partir de uma polissemia de conteúdos aos quais se aplicam os mesmos conceitos quanto de uma aparente multiplicidade de termos que remetem a uma mesma conotação. Assim, Gildo propõe um método para abordar tanto os temas quanto os autores brasileiros.

Sem negar seus "hábitos de leitura sedimentados" - para lembrar expressão de Jameson -, pois declara sempre sua dívida para com Hegel, coloca-se na posição do analista que se vê diante do objeto pela primeira vez. Suas perguntas sobre a temática e sobre os intérpretes são sempre novas. Trata-se de uma atitude constitutiva. Assumo a tentação de lhe aplicar alguns versos de Alberto Caeiro (Fernando Pessoa): "Sinto-me nascido a cada momento/ Para a eterna novidade do Mundo".

Vale lembrar que a questão do método foi uma preocupação constante da reflexão de Gildo. Duas décadas antes da publicação de sua livre-docência lembrava que "a questão de método é uma questão política. De outro modo, poderia ser supérflua ou se arriscar a permanecer formal - apesar de possíveis intenções contrárias - quando desligada e incontaminada pelas análises concretas de situações concretas" (Brandão, 1977:154). Dessa ótica, ao estudar o pensamento, afasta-se de uma leitura meramente descritiva, de uma análise que se atenha somente ao discurso e da consideração das ideias desligadas do contexto no qual são produzidas ou retomadas.

A possibilidade de estabelecer a conexão ideias/instituições políticas se dá, em sua formulação, através da pergunta: é possível captar historicamente a formação dos programas políticos das grandes correntes ideológicas do país? A busca de resposta à indagação impeliu-o a identificar e a descrever as principais "formas de pensamento" e as "famílias intelectuais" que, a partir da segunda metade do século XIX, dominaram o pensamento político brasileiro, bem como a verificar como essas correntes responderam aos desafios colocados pela sociedade e pela política. A gênese, a estrutura e as transformações de cada "família intelectual" - por hipótese, os "idealistas orgânicos", "idealistas institucionais", "pensamento radical de classe média" e "materialistas históricos", tomando emprestadas categorias cunhadas por Oliveira Vianna e Antonio Candido - são pesquisadas para indicar suas continuidades, metamorfoses e pseudometamorfoses. A análise tem por ob- 
jeto tanto o conteúdo substantivo das ideias quanto as formas de pensar subjacentes, isto é, "as estruturas mentais e categorias teóricas a partir das quais a realidade é percebida, a experiência elaborada e a ação política organizada" (id., 2009:57). Assim, volta ao clássico problema das relações forma e conteúdo que o preocupava desde aquele artigo de 1977.

Contrariando grande parte das interpretações sobre o pensamento brasileiro, Gildo demonstra que a vida ideológica brasileira não é aleatória, e que suas principais correntes não são fenômenos conjunturais. Mostra a continuidade existente entre as formulações dos denominados "intérpretes do Brasil" e as análises resultantes da pesquisa acadêmica institucionalizada. Em outros termos, nenhuma inovação intelectual parte de um espaço desabitado pelo conhecimento.

Na segunda parte de Linhagens do Pensamento Político Brasileiro, reflete sobre a teoria política a partir da periferia. Desafiado pela pergunta "por que pensar o Brasil?", Gildo primeiramente dá uma resposta aparentemente simples: "Porque se não o fizermos ninguém o fará". Contudo, o argumento ganha força em seu desdobramento. Lembrando que, embora nossos autores possam ser vistos como menores em face dos grandes intelectuais das ciências sociais, ainda assim abrem a possibilidade de transformar a fraqueza em vantagem, pois a análise da parte pode iluminar o todo. É a mesma estratégia usada por Gramsci: ao debater a questão meridional, busca apontar antes as fraquezas do sistema do que os problemas exclusivos da região sul da Itália; pensa a emancipação do sul como um momento necessário da emancipação da nação. Segundo Gildo, olhar o mundo da perspectiva da periferia pode lançar luz, a partir de um novo ângulo, sobre a natureza e a evolução da cultura, do capitalismo e da política mundiais: “Uma vez que não se pode pensar a nação nos limites da nação, não é possível pensar o Brasil sem situá-lo no mundo. Mas a maneira de fazê-lo torna possível-ou não - pensar o próprio mundo da perspectiva da periferia" (2007:142). Embora se trate de um método de análise e da avaliação de seus efeitos, a discussão é mais ampla. Trata-se de refletir sobre o papel dos intelectuais nos países periféricos.

Lembra que o quadro histórico do atraso, no qual as inúmeras tentativas "de domar nossa selvagem democracia" em uma sociedade rebelde a reduzi-la ao jogo das instituições, produz e reproduz o protagonismo dos intelectuais. Pensar um país em que a burguesia não enfren- 
tou a tarefa de incorporar seus subalternos e a intelectualidade ora se propõe "ir ao povo" ou "dar voz aos que não têm voz", ora se julga investida de um mandato em uma "advocacia gratuita" das classes sociais é a difícil temática que Gildo se propõe a deslindar.

Pelas razões expostas, pelo objetivo a ser alcançado e pelo método escolhido, fica clara sua preocupação com a fragmentação do conhecimento, sua crítica a todas as leituras parciais e sua recusa à utilização de fórmulas feitas. Só assim, de acordo com sua perspectiva, será possível reconstituir as linhas de força do pensamento político brasileiro e os processos reais por ele interpelados, provocados ou dirigidos.

Um ponto importante na análise proposta é a abordagem das crises. Nesses momentos, os paradigmas revelam suas potencialidades cognitivas e também tornam claras suas fragilidades. Na crise, as tensões se explicitam, as explicações rotinizadas perdem seu poder, e as análises são postas em outro patamar. Ou seja, a crise se apresenta em um duplo sentido. De um lado é componente da conjuntura em que as ideias emergem ou são retomadas; de outro, ganha um sentido heurístico, abrindo novas portas à reflexão.

Até o momento falei de teoria e método nos trabalhos de Gildo. Falo agora de seu comportamento diante do objeto de pesquisa. É interessante relembrar que, tanto em suas falas quanto em seus textos, raras vezes empregava o termo "concluindo". Preferia usar as expressões "tudo somado" ou, mais contundentemente, "feitas as contas". Não era apenas um modo de se expressar. Tratava-se de uma atitude diante do conhecimento e das ideias. Significava: a partir dos dados apresentados e da argumentação desenvolvida, estamos diante de novos elementos que abrem possibilidades a outras direções do pensamento. Ou seja, fizemos um balanço para, a partir dele, iniciarmos, nós ou outros, diferente etapa de investigação. É essa posição diante da vida, da política, do pensamento, dos conflitos que permite a todos que o conheceram reconhecer nele a presença de duas qualidades raramente associadas: era capaz de discutir e de lutar firmemente (e até ferozmente) por suas ideias e, ao mesmo tempo, respeitar a posição dos outros e admitir a pluralidade das opiniões.

Contribuições teórico-metodológicas, atitude impecável diante da pesquisa e valorização do trabalho coletivo são alguns pontos que destaquei como parte da herança que nos legou. No entanto, existem muitíssimas outras razões para lamentar o vazio que sua personalidade 
firme deixou. Sei que nem de longe consegui exprimir em palavras a admiração que sinto por Gildo e os laços de amizade que nos uniram.

(Recebido para publicação em maio de 2010)

\section{REFERÊNCIAS BIBLIOGRÁFICAS}

BRANDÃO, Gildo Marçal. (1977), "Totalidade e Determinação Econômica". Temas de Ciências Humanas, № 1. . (2007), Linhagens do Pensamento Político Brasileiro. São Paulo, Hucitec.

. (2009), Memorial de Atividades. Apresentado no concurso de titularidade do Departamento de Ciência Política, Faculdade de Filosofia, Ciências e Letras, Universidade de São Paulo, São Paulo. 